\title{
Correlation Between Magnetic Parameters and Chemical Composition of Lake Sediments from Northern Bohemia-Preliminary Study
}

\author{
E. Petrovský1 ${ }^{1}$, A. Kapička ${ }^{2}$, K. Zapletal ${ }^{2}$, E. Šebestová ${ }^{3}$, T. Spanilá ${ }^{3}$, M. J. Dekkers ${ }^{4}$ and P. Rochette $^{5}$ \\ ${ }^{1}$ Geophysical Institute, Czech Academy of Sciences, Bočni II/1401, 14131 Praha 4, Czech Republic \\ ${ }^{2}$ AGICO Ltd., Ječná 290, Brno, Czech Republic \\ ${ }^{3}$ Institute of the Structure and Mechanics of Rocks, Czech Academy of Sciences, 18209 Praha 8, Czech \\ Republic \\ ${ }^{4}$ Paleomagnetic Laboratory "Fort Hoofddjik", University of Utrecht, Budapestlaan 17, 3588 CD Utrecht, \\ The Netherlands \\ ${ }^{5}$ Universite d'Aix Marseille 3, CEREGE Europole de l'Arbois BP80, 13545 Aix-en-Provence, France
}

\section{Received 12 December 1996; accepted 20 November 1997}

\begin{abstract}
Recently, magnetic measurements have been used to outline areas with increased loading of toxic metals due to industrial activity. It is supposed that magnetic minerals, which are easily detectable, can carry toxic metals of anthropic origin. However, physical background of this relationship is not comprehended yet. In this study, we present our first results on statistical correlation of various magnetic parameters on one side and chemical composition on the other, obtained on sediments from the bottom of lake Nechranice, located in northern Bohemia; the captive area being typical for intensive industrial and mining activity (brown-coal basins, uranium mines, coalburning power plants). Our results suggest, that magnetic susceptibility, which has been used in other studies as indicator of increase pollution levels due to local sources, does not actually link to any of the toxic elements in concern. This finding can be explained in terms of complex inlet due to different types of pollution sources.
\end{abstract}

() 1998 Elsevier Science Ltd. All rights reserved.

\section{Introduction}

In several studies, relationship between magnetic susceptibility and concentration of toxic elements in various environments was pointed out. Linear relationship between the concentration of ferrimagnetics and the $\mathrm{Cu}$, $\mathrm{Fe}, \mathrm{Pb}$ and $\mathrm{Zn}$ content in sediment samples from urban area and near highways was found by Beckwith et al. (1986). Hunt et al. (1984) observed similar relationship between saturation isothermal remanent magnetization (SIRM) and susceptibility and $\mathrm{Pb}, \mathrm{Cu}, \mathrm{Zn}$ and $\mathrm{Cd}$ in atmospheric particulates. Hullet et al. (1980) found that certain transition elements, like $\mathrm{V}, \mathrm{Cr}, \mathrm{Mn}, \mathrm{Co}, \mathrm{Ni}, \mathrm{Zn}$ and $\mathrm{Cu}$, present in fly ash from American power plants, are associated with magnetic minerals and occur mostly in the

Correspondence to: E. Petrovský form of substituted spinels. Similar conclusion was drawn out by Dekkers and Pietersen (1992). Positive correlation between magnetic susceptibility and concentration of $\mathrm{Zn}$, $\mathrm{Pb}$ and $\mathrm{Cd}$ in Polish topsoils was found by Strzyszcz and Magiera (1993) and Strzyszcz et al. (1996). These are only few evidences that magnetic minerals, present in samples exposed to industrially derived toxic elements, are somehow related to the concentration of these elements. This relationship can be based either on incorporation of toxic elements into the lattice structure of the ferrimagnetics during combustion process, or on the adsorption onto surface of ferrimagnetics already present in the environments. The latter process is supported by findings, that goethite and haematite can adsorb e.g. $\mathrm{Cu}$, $\mathrm{Pb}, \mathrm{Zn}$, Co (Rose and Bianchi-Mosquera, 1993; Rodda et al., 1993).

This study reports on our first results of statistical correlation between magnetic parameters (magnetic susceptibility, coercive force, remanent magnetization, etc.) and chemical composition of lake sediments coming from lake Nechranice, which are supposed to contain toxic elements coming from industrial activity in the lake catchment. The aim of the study was to look for thinkable relationship between the presence of specific magnetic mineral and its physical shape on one hand and the presence of toxic elements in concern on the other.

\section{Samples and methods}

Lake Nechranice is located on Ohfe river in northern Bohemia (Fig. 1). The river catchment includes several sites of various industrial activity, e.g. brown-coal basins around Sokolovo, uranium mines close to Jáchymov, major brown-coal burning power-plants at Prunéłov, etc. Sediment samples were taken from the upper few centimeters of the lake bottom at different distance from 


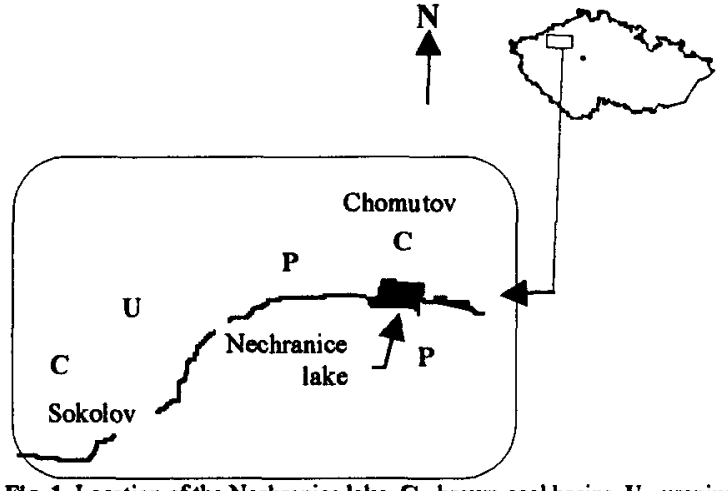

Fig. 1. Location of the Nechranice lake. C - brown-coal basins, $\mathbf{U}$ - uranium mines, $\mathbf{P}$ - coal-burning power plants.

the inlet. The samples were homogenised and dried out at moderate temperature of about $100^{\circ} \mathrm{C}$. It has to be pointed out that sampling strategy was not aimed at investigating water flow patterns or sedimentation rates. The only aim was to study chemical and magnetic properties of the samples and their mutual links.

Chemical composition was determined using ICP mass spectroscopy. Magnetic susceptibility was measured using KLF-3 Mini-kappabridge (Geofyzika Brno). To estimate the contribution of superparamagnetic particles, frequencydependent susceptibility was determined on the basis of measurements by a Bartington MS2B dual-frequency susceptibility meter. Remanent and coercive parameters were evaluated following measurements of hysteresis curves performed on Molyneux vibrating sample magnetometer. The measurements were corrected for the paramagnetic contribution. Ferrimagnetic minerals present in the samples were determined on the basis of temperature dependence of magnetic susceptibility measured using CS-2 furnace attached to KLY-2 Kappabridge (AGICO Brno, Hrouda, 1994).

Relationship between chemical composition and magnetic parameters was evaluated on the basis of correlation matrices and principal component analysis using the Statgraphics ${ }^{\mathrm{TM}}$ software.

\section{Results and discussion}

Curie point measurements revealed that all the samples contained magnetite and all except for one another magnetic phase with transition temperature at $160-170^{\circ} \mathrm{C}$. Typical behaviour of magnetic susceptibility upon heating is shown in Fig. 2. Since this transition is irreversible upon heating up to $700^{\circ} \mathrm{C}$, goethite can not be considered. The temperature stability suggests the presence of a substituted spinel. However, the amount of the sample available did not allow us to carry out X-ray analysis.

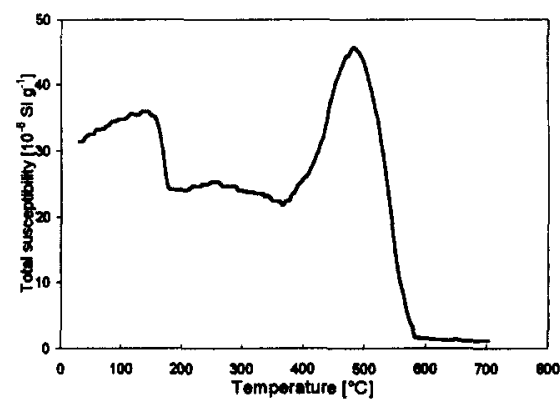

Fig. 2. Example of temperature behaviour of magnetic susceptibility, showing two magnetic transitions at $160-170^{\circ} \mathrm{C}$ (substituted spinel) and 575 $580^{\circ} \mathrm{C}$ (magnetite).

Chemical composition data obtained by ICP mass spectroscopy are listed in Table 1 (only showing the questioned elements). These toxic elements show total contents much higher than background levels as reported for the northern Bohemian region by Nexmecek et al. (1995). Magnetic parameters of the same samples are shown in Table 2; $\kappa_{l f}$ and $\kappa_{h f}$ denote low- and highfrequency susceptibility, respectively, and $f d$ represents frequency dependent magnetic susceptibility (e.g., Dearing et al., 1996). $J_{s}$ and $J_{r s}$ stand for saturation and remanent saturation magnetization, respectively, and $H_{c}$ means coercive force. For statistical correlation, two sets of elements were selected. Firstly, $\mathrm{Cu}, \mathrm{Pb}, \mathrm{Zn}, \mathrm{Ni}$ and $\mathrm{Mn}$ were considered, the elements that were reported to be adsorbed onto the surface of goethite and/or haematite (Rodda et al., 1993; Rose and Bianchi-Mosquera, 1993) or incorporated into the structure of goethite (Cornell, 1991). The other set of elements studied consists of $\mathrm{Fe}, \mathrm{Cd}, \mathrm{Ti}$ and As, the elements which were mostly found to show linear relationship with magnetic susceptibility in topsoils and atmospheric particulates (e.g., Hunt et al., 1984; Beckwith, 1986; Strzyszcz and Magiera, 1993; Strzyszcz et al., 1996).

Table 1. Chemical composition of the sediment samples (ICP Mass Spectroscopy). Only the questioned elements are listed. (Data in ppm)

\begin{tabular}{|c|c|c|c|c|c|c|c|c|c|}
\hline Sample & $\mathrm{Cu}$ & $\mathrm{Pb}$ & $\mathrm{Zn}$ & $\mathrm{Ni}$ & Mn & $\mathrm{Fe}$ & $\mathrm{Cd}$ & $\mathrm{Ti}$ & As \\
\hline NB1 & 178 & 94.0 & 339 & 1.6 & 304 & 8800 & .5 & 6070 & 59 \\
\hline N2 & & & & 173.0 & 1640 & 62350 & 5.4 & 1950 & 375 \\
\hline NB2 & 143 & 52.0 & 426 & 71.6 & 1464 & 53150 & 0.3 & 6040 & 358 \\
\hline N3 & 136 & 74.8 & 548 & 91.1 & 1471 & 55600 & 0.3 & 3930 & 260 \\
\hline NA3 & 173 & 83.2 & 615 & 79.6 & 1900 & 54200 & 1.8 & 6040 & 314 \\
\hline N5 & 187 & 81 & 68 & & 2140 & 200 & 5.0 & 6390 & 400 \\
\hline N6 & 211 & 38.7 & 41 & 89.0 & 893 & 58800 & 0.3 & 5700 & 321 \\
\hline N7 & 174 & 74.7 & 558 & 94.1 & 1790 & 55850 & 1.0 & 5565 & 400 \\
\hline N9 & 305 & 124.0 & 1079 & 100.0 & 1620 & 63800 & 7.5 & 7740 & 345 \\
\hline NA9 & 102 & 53.0 & & 2.5 & 1240 & 53100 & 1.5 & 3530 & 97 \\
\hline 111 & 181 & 75.6 & 55 & & 1430 & & 0.4 & 6430 & 229 \\
\hline 112 & 30 & 107.0 & 87 & 91.2 & 1380 & 62300 & 4.2 & 6820 & 384 \\
\hline & 19 & 92.1 & 68 & 76.9 & 1770 & 62000 & 3.9 & 6045 & 314 \\
\hline N14 & 2 & 126.0 & 1057 & 88.3 & 1932 & 59900 & 4.4 & 4690 & 185 \\
\hline & 100 & 81 & & 92. & 1712 & & 2.9 & 5924 & 327 \\
\hline & 305 & 126 & $10^{\circ}$ & 173 & 3304 & & 7.5 & 7950 & 597 \\
\hline & 102 & 38. & 36 & 62.5 & 893 & 53100 & 0.3 & 3530 & 97 \\
\hline Ben Dev. & 48 & 26.6 & 218 & 25.6 & 557 & 3574 & 2.4 & 1245 & 117 \\
\hline
\end{tabular}


Table 2. Magnetic parameters of the sediment samples; ny and ow - low- and high-frequency susceptibility, respectively, $f d$ - frequency dependent magnetic susceptibility, $J_{s}$ and $J_{n}$ - saturation and remanent saturation magnetization, respectively, and $H_{c}$ - coercive force.

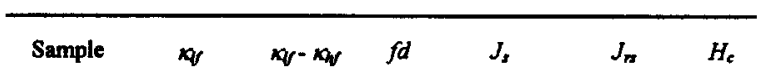

$\left[10^{-6} \mathrm{SIg}^{-1}\right]\left[10^{-6} \mathrm{SIg}^{-1}\right] \quad[\%] \quad\left[\mathrm{mAm}^{2} \mathrm{~kg}^{-1}\right]\left[\mathrm{mAm}^{2} \mathrm{~kg}^{-1}\right][\mathrm{mT}]$

\begin{tabular}{lrrrrrr}
\hline NB1 & 7.91 & 0.29 & 4.14 & 1595 & 316 & 14.3 \\
N2 & 17.99 & 0.31 & 2.07 & 1798 & 312 & 13.1 \\
NB2 & 24.51 & 0.35 & 1.34 & 2972 & 431 & 10.8 \\
N3 & 19.66 & -0.07 & -0.45 & 1860 & 247 & 9.6 \\
NA3 & 10.00 & -0.15 & -1.92 & 1319 & 217 & 12.7 \\
N5 & 7.44 & 0.23 & 1.99 & 1082 & 197 & 13.9 \\
N6 & 51.01 & 0.61 & 2.36 & 5458 & 669 & 11.0 \\
N7 & 46.79 & -0.05 & -0.12 & 7583 & 1193 & 11.8 \\
N9 & 49.06 & 0.15 & 1.92 & 2192 & 355 & 11.9 \\
NA9 & 21.20 & 0.50 & 3.50 & 2404 & 365 & 11.5 \\
N11 & 26.92 & 0.60 & 3.05 & 4608 & 517 & 8.9 \\
N12 & 13.19 & 0.41 & 4.04 & 3204 & 501 & 10.8 \\
N13 & 21.48 & 0.12 & 0.85 & 2469 & 393 & 11.5 \\
N14 & 18.96 & 0.28 & 1.53 & 2573 & 436 & 10.6 \\
\hline Average & 24.01 & 0.26 & 1.74 & 2937 & 439 & 11.6 \\
Maximum & 51.01 & 0.61 & 4.14 & 7583 & 1193 & 14.3 \\
Minimum & 7.44 & -0.15 & -1.92 & 1082 & 197 & 8.9 \\
Stand. Dev. & 14.74 & 0.24 & 1.73 & 1804 & 251 & 1.5 \\
\hline
\end{tabular}

Correlation matrices of the two sets of toxic elements and magnetic parameters studied are shown in Table 3. The correlation coefficients are presented along with the corresponding levels of confidence. Two variables that have a correlation coefficient different from zero are said to be correlated. In other words, positive correlation coefficient means that both variables increase (or decrease) at the same time. Level of confidence expresses the probability that the above observation is not by chance. This parameter can reasonably serve as a measure of significance of the correlation. For more details on correlation matrices, see e.g. Wackernagel (1995). From these results one can conclude that except for manganese,

Table 3. Correlation matrix of contents of toxic elements in concern vs. magnetic parameters studied. Upper values represent correlation coefficient, while the lower ones are levels of significance. Meaningful correlations are marked in bold typeface.

\begin{tabular}{|c|c|c|c|c|c|}
\hline & W & $H_{c}$ & $J_{n}$ & $J$ & $J_{r d} / J_{s}$ \\
\hline $\mathrm{Cu}$ & $\begin{array}{l}0.3817 \\
0.1781\end{array}$ & $\begin{array}{r}-0.0068 \\
0.9815\end{array}$ & $\begin{array}{l}0.0732 \\
0.8035\end{array}$ & $\begin{array}{l}0.0549 \\
0.8521\end{array}$ & $\begin{array}{l}0.1135 \\
0.6993\end{array}$ \\
\hline \multirow{2}{*}{$\mathrm{Pb}$} & -0.1446 & 0.0273 & -0.1296 & -0.2505 & 0.3925 \\
\hline & 0.6220 & 0.9261 & 0.6341 & 0.3878 & 0.1651 \\
\hline \multirow{2}{*}{$\mathrm{Zn}$} & -0.0158 & 0.0171 & -0.1339 & -0.2250 & 0.3441 \\
\hline & 0.9573 & 0.9536 & 0.6481 & 0.4393 & 0.2283 \\
\hline $\mathbf{M n}$ & -0.5031 & 0.6353 & $\begin{array}{r}-0.2289 \\
0.4311\end{array}$ & -0.3793 & $\begin{array}{l}0.7917 \\
0.0007\end{array}$ \\
\hline $\mathrm{Ni}$ & -0.0385 & 0.3432 & -0.0876 & -0.1446 & 0.3224 \\
\hline \multirow{2}{*}{$\mathrm{Fe}$} & 0.1236 & -0.0501 & -0.0581 & -0.0647 & 0.1314 \\
\hline & 0.6739 & 0.8651 & 0.8437 & 0.8261 & 0.6054 \\
\hline \multirow[b]{2}{*}{$\mathrm{Cd}$} & -0.1969 & 0.5943 & -0.3608 & -0.5094 & 0.7653 \\
\hline & 0.4999 & 0.0250 & 0.2051 & 0.0628 & 0.0014 \\
\hline \multirow{2}{*}{$\mathrm{Ti}$} & 0.0826 & 0.2649 & -0.0581 & -0.0766 & 0.2438 \\
\hline & 0.7789 & 0.3601 & 0.8437 & 0.7947 & 0.4010 \\
\hline$A=$ & -0.1280 & 0.5591 & 0.0644 & -0.0422 & 0.5457 \\
\hline$A B$ & 0.6627 & 0.0376 & 0.8270 & 0.8862 & 0.0436 \\
\hline
\end{tabular}

Table 4. Coefficients of first two principal components (PC) of multivariate analysis of two sets of toxic elements and magnetic parameters in question.

\begin{tabular}{|c|c|c|c|c|c|}
\hline Variable $\quad \mathrm{PC}$ & First & Second & Variable & First & Second \\
\hline $\mathrm{Cu}$ & 0.092 & -0.563 & $\mathrm{Fe}$ & 0.192 & 0.388 \\
\hline $\mathbf{Z n}$ & 0.242 & -0.523 & Cd & 0.419 & 0.184 \\
\hline $\mathrm{Pb}$ & 0.268 & -0.475 & $\mathbf{T i}$ & 0.249 & 0.430 \\
\hline $\mathrm{Ni}$ & 0.135 & 0.016 & As & 0.282 & 0.327 \\
\hline Mn & 0.380 & 0.018 & ags & -0.283 & 0.423 \\
\hline w & -0.347 & -0.296 & $H_{c}$ & 0.397 & 0.084 \\
\hline$H_{\varepsilon}$ & 0.346 & 0.149 & $J_{n}$ & -0.298 & 0.425 \\
\hline$J_{n}$ & -0.328 & -0.202 & $J_{s}$ & -0.366 & 0.396 \\
\hline$J_{s}$ & -0.401 & -0.178 & $J_{m} / J_{s}$ & 0.430 & 0.015 \\
\hline$J_{r} / J_{s}$ & 0.436 & 0.011 & $\%$ of variance & 45.37 & 25.32 \\
\hline$\%$ of variance & 40.25 & 25.72 & & & \\
\hline
\end{tabular}

neither of the elements in concern shows significant correlation with magnetic parameters sensitive to concentration of ferrimagnetic minerals (i.e. $\kappa_{l f}$ or $J_{s}$ ).

On the other hand, cadmium, arsenic and manganese show significant correlation with magnetic parameters reflecting the stability of domain structure $\left(H_{c}\right.$ and/or $J_{r}, J_{s}$ ). The observed positive correlation suggests that the more of the toxic elements is present, the wider is the hysteresis loop, or, in other words, the more stabilised are the domain walls. Low values of $f d$ (Table 2) suggest that the samples are not dominated by superparamagnetic particles; coarse multidomain grains are assumed as the dominant fraction.

Principal component analysis is one of the most widely used methods of multivariate data analysis, mainly due to its simple algebra and straightforward interpretation. A set of correlated variables is transformed into uncorrelated, orthogonal factors - principal components (Wackernagel, 1995). These are represented by linear combinations of the individual variables, explaining certain part of total variances within the data set. Variances in the data cloud can be displayed graphically by biplots in the coordinate system of the principal components, length of the vectors being indicator of the component weight (i.e. how much of the variances can be explained by this particular linear combination) and angle between each couple of vectors showing their mutual correlation. Fig. 3 shows the results of principal component analysis of the two sets of elements and magnetic parameters in concern. Coefficients of the first two principal components are listed in Table 4. Clearly, the previous results obtained by correlation matrices are confirmed. Major part of variances $(40 \%)$ within the dataset consisting of the first set of elements and magnetic parameters can be explained by linear combination, dominated by $\mathrm{Mn}, H_{c}$ and $J_{r s} / J_{s}$ with approximately the same weight. Next, $26 \%$ can be explained mainly by the concurrent presence of copper, zinc and lead. Neither of the elements correlates with concentration-dependent magnetic parameters. Similar results were obtained for cadmium and arsenic from the other set of elements. Surprisingly, iron shows correlation with neither of the magnetic parameters measured. 
A)

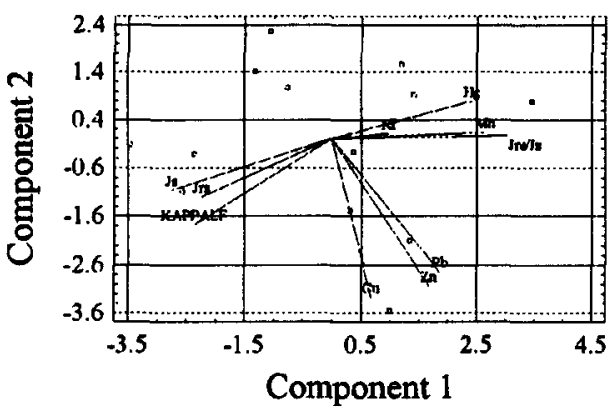

B)

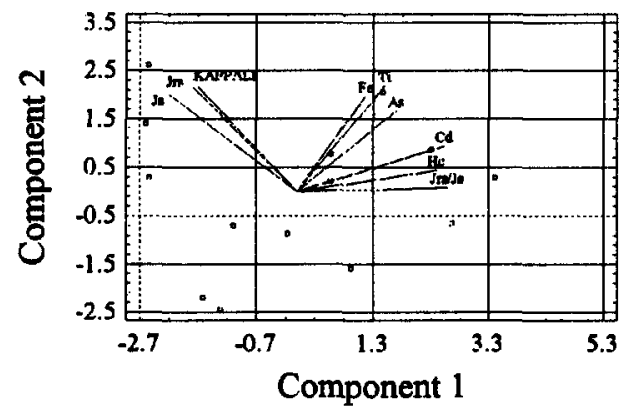

Fig. 3. Biplots of first two principal components of principal component analysis of the two sets of toxic elements and magnetic parameters studied. The principal component coefficients are listed in Table 4.

\section{Conclusions}

In this preliminary study, bottom-lake sediments from lake Nechranice in northern Bohemia were investigated. Captive area of the lake is largely affected by various industrial activities as brow-coal mines and power plants, uranium mines and steel industry. We focused on two sets of toxic elements present in the samples and their correlation with magnetic parameters. Except for manganese, neither of the elements exhibits positive relationship with magnetic susceptibility. On the other hand, cadmium, arsenic and manganese showed to be linked with coercive force and remanent to saturation magnetization ratio. This can be explained in terms of incorporation of these elements into the structure of ferrimagnetic minerals present. This idea is supported by observed temperature behaviour of magnetic susceptibility, displaying Curie temperatures corresponding to magnetite and a substituted spinel structure. Following the findings of Rodda et al. (1993) or Cornell (1991), such adsorption or incorporation is possible and can yield the increase of domain-wall pinning sites, thus resulting in the observed trend of "hardening" the hysteresis loops.

The observation that magnetic susceptibility data were practically random, independent of the contents of toxic elements, can be caused by complex effect of various pollution sources. Obviously, atmospheric particulates were not dominant as in the case of the effect of power plants alone (e.g. Hunt et al., 1994; Strzyszcz et al., 1996). Moreover, effect of dissolution of atmospheric particulates in aqueous environs can certainly bias the expected observations. Therefore, in this kind of magnetic investigation of industrial pollution, clear distinction between individual types of pollution sources has to be done, which is a challenge to our further studies.

Acknowledgements: This study was supported by the Grant Agency of the Czech Republic contract No.205/96/0260 and by an European Commission PECO Project, contract No.ERBCIPDCT940628.

\section{References}

Beckwith P.R., Ellis J.B., Revitt D.M. and Oldfield F., 1986: Heavy metal and magnetic relationships for urban source sediments. Phys. Earth Planet. Inter., 42, 67-75.

Cornell R.M., 1991: Simultaneous incorporation of $\mathrm{Mn}, \mathrm{Ni}$ and $\mathrm{Co}$ in the goethite $(\alpha \cdot \mathrm{F}-\mathrm{OOH})$ structure. Clay Minerals, 26, 427-430.

Dearing J.A., Dann R.J.L., Hay K., Lees J.A., Loveland P.J., Maher B.A. and O'Grady K., 1996: Frequency-dependent susceptibility measurements of environmental materials. Geophys. J. Inter., 124, 228-240.

Dekkers M.J. and Pietersen H.S., 1992: Magnetic properties of low-Ca fly ash: a rapid tool for Fe-assessment and a survey for potentially hazardous elements. In: E.P. Glasser, G.J. MoCarthy, J.F. Young, T.O. Mason and P.L. Pratt (eds), Advanced Cementitous Systems: Mechanism and Properties, Mat. Res. Soc. Symp. Proc., 245, 37-47.

Hrouda F., 1994: A technique for the measurement of thermal changes of magnetic susceptibility of weakly magnetic rocks by the CS-2 apparatus and KLY-2 Kappabridge. Geophys. J. Inter., 118, 604-612.

Hullet L.D., Weisberger A.J., Northeutt K.J. and Ferguson M., 1980: Chemical species in fly ash from coal-buming power plants. Science, 210, 1356-1358.

Hunt A., Jones J. and Oldfield F., 1984: Magnetic measurements and heavy metals in atmospheric particulates of anthropogenic origin. Sci. Total Environ., 33, 129-139.

Němexek J., Podlešáková E. and Pastuszková M., 1995: Background contents of the potentially hazardous elements in soils of the Czech Republic (contents in the 2M HNO, extract). Rostlinnó výroba, 41, 25-29 (in Czech with English summary).

Rodda D.P., Johnson B.B. and Wells J.D., 1993: The effect of temperature and $\mathrm{pH}$ on the adsorption of copper (II), lead(II) and zinc(II) onto goethite. J. Colloid Interf. Sci., 161, 57-62.

Rose A.W. and Bianchi-Mosquera G.C., 1993: Adsorption of $\mathrm{Cu}, \mathrm{Pb}, \mathrm{Zn}$, $\mathrm{Co}, \mathrm{Ni}$ and $\mathrm{Ag}$ on goethite and hematite: a control on metal mobilization from red-beds into stratiform copper deposits. Economic Geology. 88, 1226-1236.

Strzyszcz Z. and Magiera T., 1993: Ferromagnetism of soils in Polish Natural Parks and its use in monitoring of forest ecosystems. Pradnik. Prace Muz. Szafera, 7-8, 125-132 (in Polish).

Strzyszcz Z., Magiera T. and Heller F., 1996: The influence of industrial immissions on the magnetic susceptibility of soils in Upper Silesia. Studia geoph. geod., 40, 276-286.

Wackernagel H., 1995. Multivariate Geostatistics. Springer-Verlag, Berlin, 1995. 